\title{
First report of Setaria tundra in roe deer (Capreolus capreolus) from the Iberian Peninsula inferred from molecular data: epidemiological implications
}

\author{
Samer Angelone-Alasaad ${ }^{1,2^{*}+}$ (D) Michael J. Jowers ${ }^{3,4+}$, Rosario Panadero ${ }^{5}$, Ana Pérez-Creo ${ }^{5}$, Gerardo Pajares ${ }^{5}$, \\ Pablo Díez-Baños ${ }^{5}$, Ramón C. Soriguer ${ }^{1}$ and Patrocinio Morrondo ${ }^{5}$
}

\begin{abstract}
Background: Filarioid nematode parasites are major health hazards with important medical, veterinary and economic implications. Recently, they have been considered as indicators of climate change.

Findings: In this paper, we report the first record of Setaria tundra in roe deer from the Iberian Peninsula. Adult S. tundra were collected from the peritoneal cavity during the post-mortem examination of a 2 year-old male roe deer, which belonged to a private fenced estate in La Alcarria (Guadalajara, Spain). Since 2012, the area has suffered a high roe deer decline rate $(75 \%)$, for unknown reasons. Aiming to support the morphological identification and to determine the phylogenetic position of $\mathrm{S}$. tundra recovered from the roe deer, a fragment of the mitochondrial cytochrome c oxidase subunit 1 (cox1) gene from the two morphologically identified parasites was amplified, sequenced and compared with corresponding sequences of other filarioid nematode species. Phylogenetic analyses revealed that the isolate of $\mathrm{S}$. tundra recovered was basal to all other formely reported Setaria tundra sequences. The presence of all other haplotypes in Northern Europe may be indicative of a South to North outbreak in Europe.

Conclusions: This is the first report of S. tundra in roe deer from the Iberian Peninsula, with interesting phylogenetic results, which may have further implications in the epidemiological and genetic studies of these filarioid parasites. More studies are needed to explore the reasons and dynamics behind the rapid host/geographic expansion of the filarioid parasites in Europe.
\end{abstract}

Keywords: Filarioid, Mitochondrial cytochrome c oxidase subunit 1 (cox1), Phylogenetics, Epidemiology, Climate change, Bayesian inference analysis

\section{Background}

Filarioid nematode parasites are major health hazards with significant medical, veterinary and economic implications, with millions of people and animals globally affected [1]. Haematophagous arthropods are the vectors of these parasites [2], which have recently been considered as indicators of climate change [3, 4]. Filarioid

\footnotetext{
* Correspondence: sameralasaad@hotmail.com

${ }^{\dagger}$ Equal contributors

${ }^{1}$ Estación Biológica de Doñana, Consejo Superior de Investigaciones Científicas (CSIC), Sevilla, Spain

${ }^{2}$ Institute of Evolutionary Biology and Environmental Studies (IEU), University of Zurich, Zurich, Switzerland

Full list of author information is available at the end of the article
}

parasites are difficult to control due to vectors' mobility and/or the risk of resistance to drugs [5].

The phylogenetic relationships of filarioid parasites have been assessed on morphological characters [6, 7]. Nevertheless, molecular analyses are needed to confirm their morphological descriptions or taxonomic position and classification, and to improve our understanding of the species epidemiology $[5,8]$.

In Europe, Setaria tundra has been reported from Germany [9, 10], Bulgaria [11], Sweden [12], Norway [13], the Baikal area [14], Italy [15], Poland [16] and Finland [17]. Setaria tundra is considered as a common parasite in the northern hemisphere, especially in Finland, where 
mass infection has occurred [17]. Here there seems to be a correlation of infection to wetland areas, where $S$. tundra vectors (mosquitoes) are at their optimal microclimate condition and reindeer herds are present [18], with 30$40 \%$ of all S. tundra outbreaks in Finland.

The aims of the present study were to: (i) Report for the first time $S$. tundra in the roe deer Capreolus capreolus from the Iberian Peninsula, and (ii) examine the phylogenetic position of the newly-found $S$. tundra, based on sequences of the mitochondrial cytochrome $c$ oxidase subunit 1 ( $\operatorname{cox} 1)$ gene.

\section{Methods}

\section{Case report, sample collection and morphological examination}

During the last 3 years, a private fenced estate in La Alcarria (Guadalajara, Spain) has suffered from a decline of $75 \%$ of roe deer population for unknown reasons. Moreover, lower body weight and reduction of trophy size in males have been noted. Roe deer in this fenced estate are native animals (the density before decline was c. 30 animals per $100 \mathrm{ha}$ ). In the study area, there are no domestic animals. The sympatric wild animals are the wild boar Sus scrofa, the red fox Vulpes vulpes and the European badger Meles meles, together with different bird species, which interact with roe deer, namely the golden eagle Aquila chrysaetos, the griffon vulture Gyps fulvus and the cinereous vulture Aegypius monachus.

To identify the reason behind the high population decline, the owner sent on the 5th of April 2016, the carcass of a 2 year-old male roe deer to the INVESAGA laboratory at the Faculty of Veterinary Medicine in Lugo for post-mortem examination. The animal was apparently in poor body condition. During necropsy, two adult females of Setaria tundra were collected from the peritoneal cavity (Fig. 1). Nematodes were preserved at room temperature in $70 \%$ ethanol and then stained with $0.01 \%$ cotton blue in lactophenol before morphological identification, and later DNA extraction. Setaria specimens were identified as $S$. tundra based on morphological characteristics described in [19] (Fig. 1).

\section{DNA extraction}

Genomic DNA was extracted from each of the two S. tundra specimens using DNeasy Blood \& Tissue Kit (Quigen, Hilden, Germany). DNA extractions were carried out in a sterilized laboratory dedicated exclusively for low DNA concentration samples. Two blanks (reagents only) were included in each extraction to monitor for contamination.

\section{PCR and sequencing of the mitochondrial cox 1 gene}

The methods of Casiraghi et al. [20] for PCR amplification of the partial cox 1 gene, were followed. The $30-\mu \mathrm{l}$

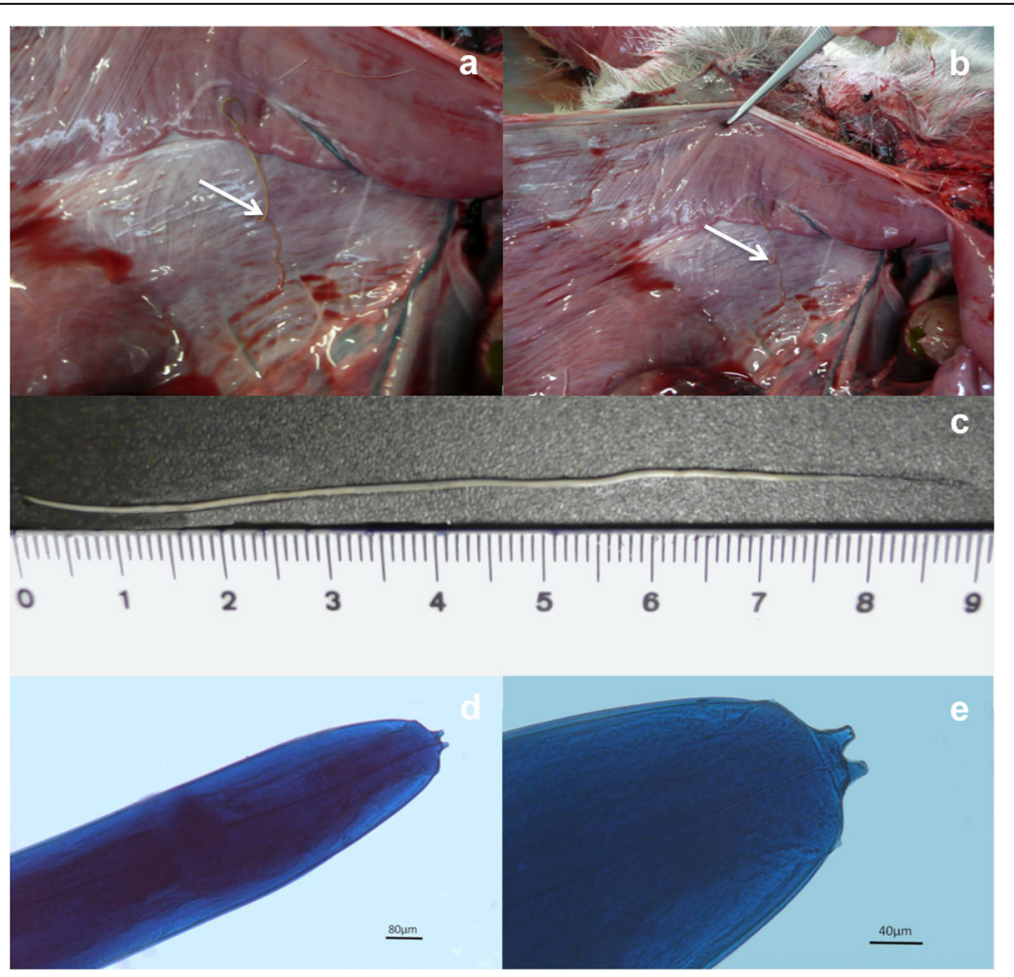

Fig. 1 Images showing a, b necropsy of the peritoneal cavity of the roe deer with adult Setaria tundra, $\mathbf{c}$ the recovered parasites, and photomicrographs of S. tundra (d, e) 
PCR mixture contained $2 \mu \mathrm{l}$ of template DNA, $0.25 \mu \mathrm{M}$ of the primers coxlintF ( $5^{\prime}$-TGA TTG GTG GTT TTG GTA A-3') and coxlintR (5'-ATA AGT ACG AGT ATC AAT ATC-3'), $0.12 \mathrm{mM}$ of each dNTP, $3 \mu \mathrm{l}$ of PCR buffer (Bioline, Sydney, Australia), $1.5 \mathrm{mM} \mathrm{MgCl} 2,0.4 \%$ BSA, $1.5 \mu \mathrm{l}$ DMSO, and $0.2 \mu \mathrm{l}(0.2 \mathrm{U} /$ reaction) Taqpolymerase (Bioline). The following thermal profile for amplification in a PTC0200 thermal cycler (Bio-Rad) was used: 4 min at $94{ }^{\circ} \mathrm{C}$ (initial denaturation), followed by 30 cycles of three steps of $1 \mathrm{~min}$ at $94{ }^{\circ} \mathrm{C}$ (denaturation), $1 \mathrm{~min}$ at $52{ }^{\circ} \mathrm{C}$ (annealing), and $50 \mathrm{~s}$ at $72{ }^{\circ} \mathrm{C}$ (extension), before a final elongation of $5 \mathrm{~min}$ at $72{ }^{\circ} \mathrm{C}$. PCR blanks (reagents only) were included.

Sequencing was carried out in both directions using the BigDye $^{\bullet}$ Terminator v1.1 cycle sequencing kit (Applied Biosystems) according to the manufacturer's instructions. Labelled fragments were resolved on an automated A3130xl genetic analyser (Applied Biosystems).

\section{Molecular analyses}

Amplicons were sequenced on both strands, and the complementary reads were used to resolve rare, ambiguous base-calls in Sequencher v.4.9. Additionally, BLAST searches were conducted in GenBank and matches with high genetic affinity were downloaded and included in the alignment, with a cut-off point at $91 \%$ genetic similarity. Higher genetic divergence recovered from other homologous sequences from Setaria spp. were downloaded and included in the alignment. The selected outgroup was Thelazia callipaeda. Sequences were aligned in SeaView v.4.2.11 [21] under ClustalW2 [22] default settings. The most appropriate substitution model for the Bayesian Inference (BI) analysis was determined by the Bayesian Information Criterion (BIC) in jModeltest v.2 [23]. MrBayes v.3.2.6 [24] was used with default priors and Markov chain settings, and with random starting trees. Each run consisted of four chains of 20,000,000 generations, sampled each 10,000 generations and posterior distributions of parameter estimates were visually inspected in Tracer v1.5 [25]. A plateau was reached after few generations with $25 \%$ of the trees resulting from the analyses discarded as 'burn-in'. Phylogenetic relationships among haplotypes were estimated using a Maximum Likelihood (ML) approach, as implemented in the software RAxML v7.0.4 [26], using the default settings. The $50 \%$ bootstrap consensus tree was built in PAUP 4 [27]. All analyses were performed through the CIPRES platform [28].

\section{Results and discussion}

In this paper, we report the first record of Setaria tundra in roe deer from the Iberian Peninsula. The parasites were identified morphologically and genetically, based on the sequences of a fragment of the mitochondrial cytochrome $c$ oxidase subunit $1(\operatorname{cox} 1)$ gene. The newlyobtained sequences were submitted to GenBank (KX599455-KX599456). The alignment length was $637 \mathrm{bp}$. GenBank blast matched Setaria tundra, with 99 \% similarity and a highest divergence (similarity of $98 \%$ ) to the isolate 71YT MNHN (KP760209) with $10 \mathrm{bp}$ substitutions. The closest match of the present isolate was to isolates 6615 (KF692104) and 5808 (KF692103) from Germany, with only two bp substitutions.

In the phylogenetic analysis, the best-fitting model identified was the $\operatorname{TrN}+\mathrm{I}+\mathrm{G}(-\operatorname{lnL}=2610.81847, \mathrm{BIC}=$ 5602.586350). The Effective Sample Size (ESS) values for all runs were over 1,800 , thus confirming good convergence mixing of all mcmc (Markov Chain Monte Carlo) runs. All analyses recovered a well-resolved monophyletic clade of Setaria tundra (Bayesian posterior probability (Pp) of 1; ML bootstrap $100 \%$ ) with the position of the new sequence basal to the remaining haplotypes (Fig. 2). All terminal clades recovered high support in all analyses and all species were monophyletic (Pp: 1.00).

The recovered phylogenetic tree showing two monophyletic clades of unidentified nematodes within Setaria may suggest paraphyly of the genus (Fig. 2), which demands further taxonomic assessment within Setaria. The basal positioning of Setaria tundra recovered from this study suggests ancestry to all known European $S$. tundra haplotypes. Thus, although ancestral, its presence may have been undetected until now by limited case studies such as this one. The presence of all other haplotypes in northern Europe may be indicative of a South to North European outbreak route rather than the opposite. Further molecular taxonomic identification is needed to assess the extent of the parasite range in the Iberian Peninsula, the host species and parasite genetic diversity. Through such sampling the ancestral and descendent populations could elucidate important information regarding intermediate populations likely to be infected by Setaria that are currently unrecorded.

Other studies have found C. capreolus to be the host for S. tundra in Germany [29], Bulgaria [11], Italy [15], Finland [30] and Poland [16]. Our study thus increases the host infective range from Northern to Southern Europe, as well as the parasite range. Several are the candidate insect vectors for Setaria spp. infections [17, 31]. Mammophilic mosquitoes, Aedes spp. and Anopheles spp., have shown to have an important role in the transmission of S. tundra in Finland, which suggests that this parasite is probably not vector-specific, and this consequently enhances the ability of $S$. tundra to expand geographically. Infections with $S$. tundra in reindeer herds in Finland are associated to wetlands, with fresh food pastures and drinking water, where mosquito populations are at their optimum microclimate condition to thrive [18]. The presence of $S$. tundra here seems to be related to herd 


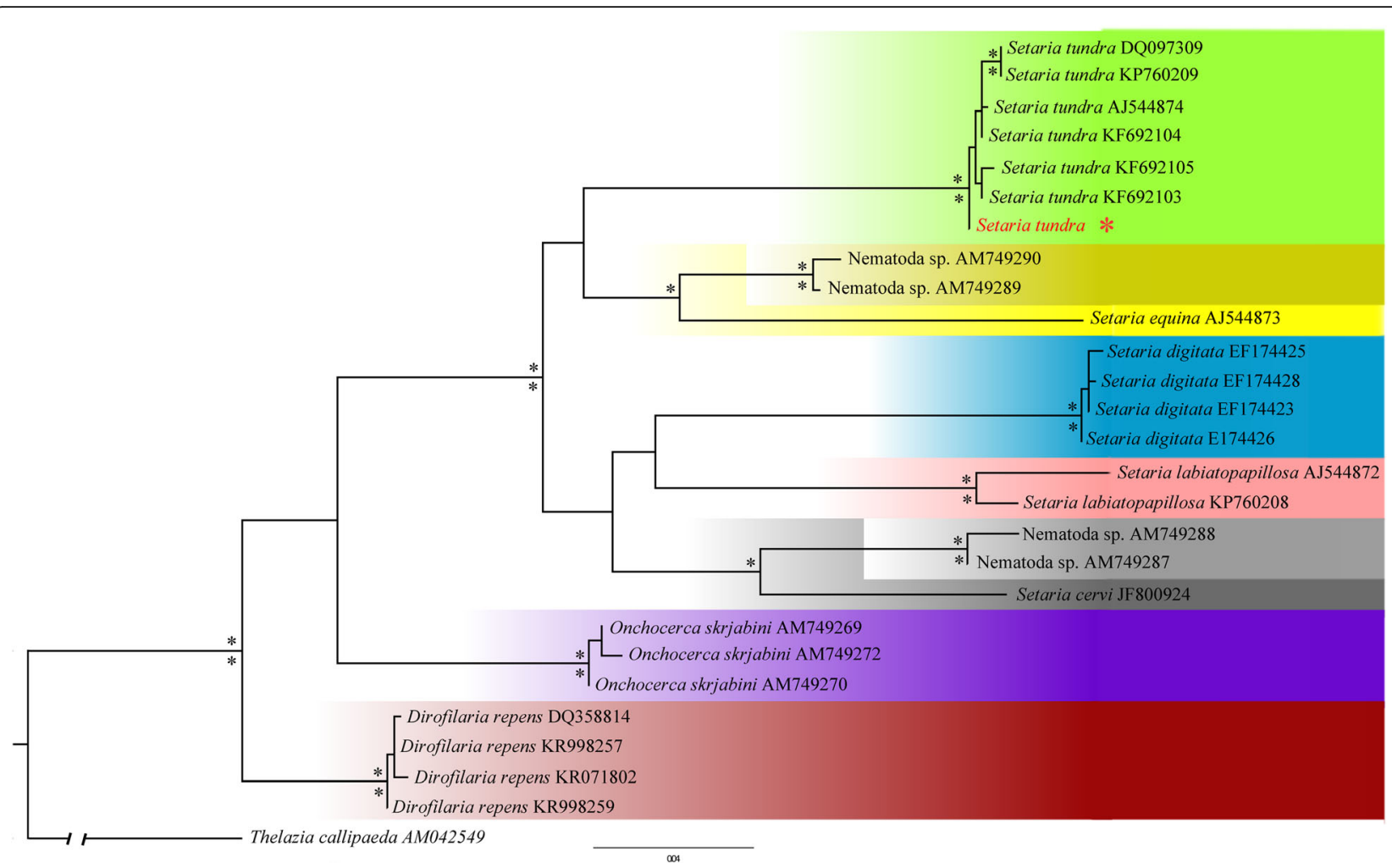

Fig. 2 Best maximum likelihood (ML) tree for the cox1 (637 bp) dataset of filarioid sequences including the newly-recovered Setaria tundra haplotype in red. Asterisk $\left(^{*}\right)$ on and under nodes are posterior probabilities (Pp) recovered from the Bayesian analysis and bootstrap support from the ML $50 \%$ majority-rule consensus tree ( $\geq 95 \%$ ), respectively. The following GenBank accession numbers recovered the same haplotypes and only one GenBank sequence per haplotype is included in the tree: Onchocerca skrjabini (AM749269, AM749271), Dirofilaria repens (AB973225, KT901783, DQ358814), Setaria digitata (EF174428, EF174427), Setaria digitata (EF174424, EF174423, GU138699), Setaria tundra (KF692104, KK692106), Setaria tundra (KM452922, AM749298, KF692103)

migrations, with a decline in the presence of $S$. tundra in hosts or mosquitoes in the Upper Lapland [17, 32]. These data are key to assess the likely areas to conduct surveys in the Iberian Peninsula and to establish molecular screening protocols for possible vectors and hosts. The ecological and topographical conditions at the La Alcarria conform to the vectors' optimal environmental conditions. Furthermore, the presence of permanent water and the closure of the herd prevent animals to avoid possible high-risk infectious areas by migration. The Scandinavian (1973) S. tundra outbreak was associated to an exceptional warm period and high numbers of possible vectors such as mosquitoes and gnats [33]. Thus, further studies are needed to assess the possible impact of climate change on transmission dynamics of Setaria spp. in Europe [4].

\section{Conclusions}

This is the first report of Setaria tundra in roe deer from the Iberian Peninsula, with interesting phylogenetic results, which may have further implications in the epidemiological and genetic studies of filarioid nematode parasites. More studies are needed to explore the reasons and dynamics behind the rapid host/geographical expansion of filarioid parasites in Europe.

\section{Acknowledgements}

This work was supported by the Programme for Consolidating and Structuring Competitive Research Groups (GRC2015/003, Xunta de Galicia). Molecular analyses were carried out in the LEM of EBD, CSIC and funded by RNM 118; Junta Andalucia. The authors express their gratitude to the Asociación del Corzo Español (ACE), which facilitated sample collection of the animals.

\section{Funding}

Not applicable.

\section{Availability of data and material}

The datasets supporting the conclusions of this article are included within the article. Sequences are submitted to the GenBank database under accession numbers KX599455-KX599456.

\section{Authors' contributions}

RP, APC, GP, PDB, and PM performed the necropsy and the morphological identification of the parasites. SAA, MJJ and RCS did the genetic characterization and phylogenetic analyses. SAA, MJJ, RP, APC, GP, PDB, RCS, and PM discussed and wrote the paper. All authors read and approved the final version of the manuscript.

\section{Competing interests}

The authors declare that they have no competing interests.

\section{Consent for publication}

Not applicable. 


\section{Ethics approval and consent to participate}

Not applicable.

\section{Author details}

${ }^{1}$ Estación Biológica de Doñana, Consejo Superior de Investigaciones Científicas (CSIC), Sevilla, Spain. ${ }^{2}$ Institute of Evolutionary Biology and Environmental Studies (IEU), University of Zurich, Zurich, Switzerland. ${ }^{3} \mathrm{CIBIO} /$ InBIO (Centro de Investigação em Biodiversidade e Recursos Genéticos), Universidade do Porto, Campus Agrario De Vairão, 4485-661 Vairão, Portugal. ${ }^{4}$ National Institute of Ecology, 1210, Geumgang-ro, Maseo-myeon, Seocheon-gun, Chungcheongnam-do 33657, Korea. ${ }^{5}$ INVESAGA Group, Departamento de Patología Animal. Facultad de Veterinaria, Universidad de Santiago de Compostela, 27071, Lugo, Spain.

Received: 25 July 2016 Accepted: 6 September 2016 Published online: 29 September 2016

\section{References}

1. World Health Organization. Global programme to eliminate lymphatic filariasis: annual report on lymphatic filariasis 2006. Wkly Epidemiol Record. 2007;82:361-80.

2. Anderson RC. The superfamily Filaroidea. In: In nematode parasites of vertebrates. Their development and transmission. 2nd ed. New York: CABI Publishing: 2000. p. 467-529.

3. Genchi C, Rinaldi L, Mortarino M, Genchi M, Cringoli G. Climate and Dirofilaria infection in Europe. Vet Parasitol. 2009:163:286-92.

4. Laaksonen S, Pusenius J, Kumpula J, Venäläinen A, Kortet R, Oksanen HE. Climate change promotes the emergence of serious disease outbreaks for Filarioid nematodes. Ecohealth. 2010;1:7-13.

5. Yatawara L, Wickramasinghe S, Nagataki M, Rajapakse RPVJ, Agatsuma T. Molecular characterization and phylogenetic analysis of Setaria digitata of Sri Lanka based on CO1 and 12S rDNA genes. Vet Parasitol. 2007;148:161-5.

6. Chabaud AG, Bain O. The evolutionary expansion of the Spirurida. Int J Parasitol. 1994;24:1179-201.

7. Bain O. Evolutionary relationships among filarial nematodes. In: Chabaud AG, Bain O, editors. 1976. La lignée Dipetalonema. Nouvel essai de classification. Ann Parasitol Hum Comp, vol. 51. 2002. p. 365-97.

8. Alasaad S, Pascucci I, Jowers MJ, Soriguer RC, Zhu XQ, Rossi L. Phylogenetic study of Setaria cervi based on mitochondrial cox1 gene sequences. Parasitol Res. 2012;110:281-5.

9. Rehbein S, Lutz W, Visser M, Winter R. BeiträgezurKenntnis der Parasitenfauna des Wildes in Nordrhein-Westfalen.1. Der Endoparasitenbefall des Rehwildes. Z Jagdwiss. 2000;46:248-69.

10. Czajka C, Becker N, Poppert S, Jöst H, Schmidt-Chanasit J, Andreas KA. Molecular detection of Setaria tundra (Nematoda: Filarioidea) and an unidentified filarial species in mosquitoes in Germany. Parasit Vectors. 2012;5, e14.

11. Yanchev $Y$. The helminth fauna of roe deer (Capreolus capreolus) in Bulgaria. 3. Material on helminth fauna in roe deer (Capreolus capreolus L.) in the mountains of southern Bulgaria. Izv Tsentr Khelmintol Lab. 1973;16:205-20 (In Bulgarian)

12. Rehbinder C, Christensson D, Glatthard V. Parasitic granulomas in reindeer. A histopathological, parasitological and bacteriological study. Nord Vet Med. 1975:27:499-507.

13. Kummeneje K. Diseases in reindeer in northern Norway. In: Proceedings of the Symposium of the Second International Reindeer - Caribou Symposium in Roros 17-21 September Part B, Norway. 1979. 1980. p. 456-8.

14. Shagraev MA, Zhaltsanova DSD. Fauna I resursy pozvonochnykh basseina ozera Baikal. In: A study of the helminth fauna of domestic deer in the Buryat ASSR. 1980. p. 128-30. In Russian with English abstract

15. Favia G, Cancrini G, Ferroglio E, Casiraghi M, Ricci I, Rossi L. Molecular assays for the identification of Setaria tundra. Vet Parasitol. 2003:117:139-45.

16. Kowal J, Kornaś S, Nosal P, Basiaga M, Lesiak M. Setaria tundra in roe deer (Capreolus capreolus) new findings in Poland. Ann Parasitol. 2013:59:179-82.

17. Laaksonen S, Solismaa M, Kortet R, Kuusela J, Oksanen A. Vectors and transmission dynamics for Setaria tundra (Filarioidea; Onchocercidae), a parasite of reindeer in Finland. Parasit Vectors. 2009;2, e3.

18. Anderson JR, Nilssen A. Do reindeer aggregate on snow patches to reduce harassment by parasitic flies or thermoregulate? Rangifer. 2008;18:3-17.

19. Nikander S, Laaksonen S, Saari S, Oksanen A. The morphology of the filaroid nematode Setaria tundra, the cause of peritonitis in reindeer Rangifer tarandus. J Helminth. 2007:81:49-55.
20. Casiraghi M, Anderson TJC, Bandi C, Bazzocchi C, Genchi C. A phylogenetic analysis of filarial nematodes: comparison with the phylogeny of Wolbachia endosymbionts. Parasitology. 2001;122:93-103.

21. Gouy M, Guindon S, Gascuel O. SeaView version 4. A multiplatform graphical user interface for sequence alignment and phylogenetic tree building. Mol Phylogenet Evol. 2010;27:221-4.

22. Larkin MA, Backshields G, Brown NP, Chenna R, McGettigan PA, McWilliam $\mathrm{H}$, et al. Clustal W and Clustal X version 2.0. Bioinfomatics Application Note. 2007:23:2947-8

23. Posada D. jModelTest: Phylogenetic model averaging. Mol Biol Evol. 2008;25: 1253-6.

24. Ronquist F, Huelsenbeck JP. MRBAYES 3: Bayesian phylogenetic inference under mixed models. Bioinformatics. 2003;19:1572-4.

25. Rambaut A, Drummond AJ. Tracer v1.5. Available at: http://beast.bio.ed.ac. uk/Tracer 2007

26. Silvestro D, Michalak I. A user friendly graphical front-end for phylogenetic analyses using RAxML (Stamatakis, 2006). Org Divers Evol. 2010;12:335-7.

27. Swofford DL. PAUP. Phylogenetic Analysis Using Parsimony (and Other Methods). Version 4. Sunderland: Sinauer Associates; 2002.

28. Miller MA, Pfeiffer W, Schwartz T. Creating the CIPRES Science Gateway for inference of large phylogenetic trees. New Orleans: Proceedings of the Gateway Computing Environments Workshop (GCE); 2010. p. 1-8.

29. Buttner K. A study on parasites of roe deer in Steigerwald. Waldhygiene. 1975;11:83-100.

30. Laaksonen S, Solismaa M, Orro T, Kuusela J, Saari S, Kortet R, et al. A: Setaria tundra microfilariae in reindeer and other cervids in Finland. Parsitol Res. 2009;104:257-65.

31. Laaksonen S, Oksanen S. Status and review of the vector-borne nematode Setaria tundra in Finnish cervids. Alces. 2009;45:81-4.

32. Kumpula J, Colpaert A, Nieminen M. Suomen poronhoitoalueen kesälaidunvarat. The summer pasture recourses of the Finnish reindeer management area. In: Kala-ja riistaraportteja nro 152. Kaamanen: Riistan-ja kalantutkimus: 1999. p. 40-6. In Finnish, English abstract.

33. Rehbinder C. Some vector borne parasites in Swedish reindeer (Rangifer tarandus tarandus). Rangifer. 1990;10:67-73.

\section{Submit your next manuscript to BioMed Central and we will help you at every step:}

- We accept pre-submission inquiries

- Our selector tool helps you to find the most relevant journal

- We provide round the clock customer support

- Convenient online submission

- Thorough peer review

- Inclusion in PubMed and all major indexing services

- Maximum visibility for your research

Submit your manuscript at www.biomedcentral.com/submit
C) Biomed Central 